\title{
Management of Germ Cell Tumors in Children: Approaches to Cure
}

\author{
U. Göbel ${ }^{\mathrm{a}}$ G. Calaminus ${ }^{\mathrm{a}}$ D.T. Schneider ${ }^{\mathrm{a}}$ P. Schmidt ${ }^{\mathrm{b}}$ R.J. Haas ${ }^{\mathrm{b}}$, on behalf of the MAKEl and \\ MAHO Study Groups of the German Society of Pediatric Oncology and Hematology, and the SIOP \\ CNS GCT Study Group
}

${ }^{a}$ Clinic of Pediatric Hematology and Oncology, Heinrich-Heine University, Medical Center, Düsseldorf

${ }^{b}$ Clinic of Pediatric Hematology and Oncology, Ludwig-Maximilians University, Munich

Key Words

Germ cell tumors · Children · Adolescents

\section{Summary}

The introduction of cisplatinum chemotherapy and current advances in the surgical treatment have resulted in a dramatic improvement of the prognosis of children with malignant germ cell tumors (GCT). Cisplatinum chemotherapy generally results in sufficient systemic tumor control, but local relapses may still occur in patients who did not receive adequate local treatment. Therefore, the therapeutic consideration must take into account age, primary site of the tumor, and its histology. In gonadal tumors, there is a high chance of primary complete resection since these tumors tend to be encapsulated, and particularly testicular GCT are often detected at a low tumor stage. In contrast, a primary complete resection may be impossible in large nongonadal tumors such as sacrococcygeal or mediastinal GCT. In these tumors, a neoadjuvant or preoperative chemotherapy after clinical diagnosis by imaging and evaluation of tumor markers significantly facilitates complete resection on delayed surgery. In addition, the impact of chemotherapy on local tumor control may be enhanced by locoregional hyperthermia. In most intracranial GCT complete resection is impossible and may be associated with significant morbidity. Nevertheless, biopsy is essential for diagnosis in nonsecreting tumors. In intracranial $\mathrm{GCT}$, radiotherapy significantly contributes to local tumor control, and doses are stratified according to histology. These general considerations have been integrated into national and international cooperative treatment protocols. In most current protocols, treatment is stratified according to an initial risk assessment that includes the parameters age, site, histology, stage, completeness of resection and the tumor markers alpha ${ }_{1}$-fetoprotein (AFP) and human choriogonadotropin ( $\beta$-HCG). With such modern protocols overall cure rates above $80 \%$ can be achieved. Moreover, the previously highrisk groups may now expect a favorable prognosis with this riskadapted treatment, whereas an increasing number of low-risk patients are treated expectantly or with significantly reduced chemotherapy. As current biologic studies reveal distinct genetic patterns in childhood GCT, it can be expected that further combined clinical and genetic studies will be valuable for risk assessment of childhood GCT.
Schlüsselwörter

Keimzelltumoren $\cdot$ Kinder $\cdot$ Jugendliche

\section{Zusammenfassung}

Mit der Einführung der cisplatinhaltigen Chemotherapie und der Optimierung der chirurgischen Behandlung hat sich die Prognose der malignen Keimzelltumoren (KZT) bei Kindern dramatisch verbessert. Die cisplatinhaltige Chemotherapie resultiert in der Regel in einer guten systemischen Tumorkontrolle. Jedoch können lokale Rezidive auftreten, wenn keine ausreichende lokale Behandlung erreicht wird. Daher müssen die Parameter Alter, primäre Tumorlokalisation und Histologie in den therapeutischen Überlegungen berücksichtigt werden. Bei den meisten gonadalen KZT kann eine komplette Tumorresektion erreicht werden, da diese oft eine Tumorkapsel haben und besonders Hodentumoren zumeist früh erkannt werden. Dagegen ist eine komplette primäre Resektion bei vielen extragonadalen KZT z.B. der Steißbeinregion oder des Mediastinums nicht möglich. Hier erleichtert eine präoperative oder neoadjuvante Chemotherapie nach klinischer Diagnosestellung anhand der radiologischen Befunde und der Tumormarker-Konstellation die komplette Tumorentfernung während der verzögerten Tumorresektion. In besonderen Fällen kann der Effekt der Chemotherapie auf die lokale Tumorkontrolle durch eine lokoregionale Tiefenhyperthermie-Behandlung potenziert werden. Bei intrakranialer Lokalisation ist die komplette Resektion oft unmöglich und teilweise mit schwerwiegenden Komplikationen behaftet. Daher ist bei nichtsezernierenden KZT eine Tumorbiopsie notwendig. Die Radiotherapie, deren Dosis entsprechend der Histologie stratifiziert wird, kann signifikant zur lokalen Tumorkontrolle der intrakranialen KZT beitragen, so dass in ausgewählten Fällen keine Resektion erforderlich ist. Diese allgemeinen Erwägungen werden in nationalen und internationalen kooperativen Therapiestudien berücksichtigt. In den meisten aktuellen Protokollen wird die Therapie risikostratifiziert anhand der Parameter Alter, Lokalisation, Histologie, Stadium, Resektionsstatus und der Tumormarker Alpha 1 -Fetoprotein (AFP) und humanes Choriogonadotropin ( $\beta$-HCG). Innerhalb dieser Studien werden für die Gesamtgruppe Heilungsraten über $80 \%$ erreicht. Darüber hinaus konnte die Prognose der früheren Hochrisiko-Gruppen deutlich gebessert werden, während eine zunehmende Zahl von Niedrigrisiko-Patienten nach der Operation ausschließlich nachbeobachtet oder mit deutlich reduzierter Chemotherapie behandelt wird. Da aktuelle molekularbiologische Studien differenzierte genetische Muster bei KZT im Kindes- und Jugendalter aufzeigen, die sich von denen bei KZT im Erwachsenenalter unterscheiden, ist zu erwarten, dass zukünftige kombinierte klinische und genetische Studien für die Risikobeurteilung bei KZT bei Kindern hilfreich sein werden.

\begin{tabular}{ll}
\hline KARGER & $($ 2002 S. Karger GmbH, Freiburg \\
$\begin{array}{l}\text { Fax +497614520714 } \\
\begin{array}{l}\text { E-mail Information@Karger.de } \\
\text { www.karger.com }\end{array}\end{array}$ & Accessible online at: \\
www.karger.com/journals/onk
\end{tabular}

Prof. Dr. U. Göbel

Klinik für Pädiatrische Hämatologie und Onkologie

Heinrich-Heine-Universität, Zentrum für Kinderheilkunde

Moorenstraße 5, D-40225 Düsseldorf (Germany)

Tel. +49 211 811-76 80, Fax -62 06

E-mail makei@med.uni-duesseldorf.de 


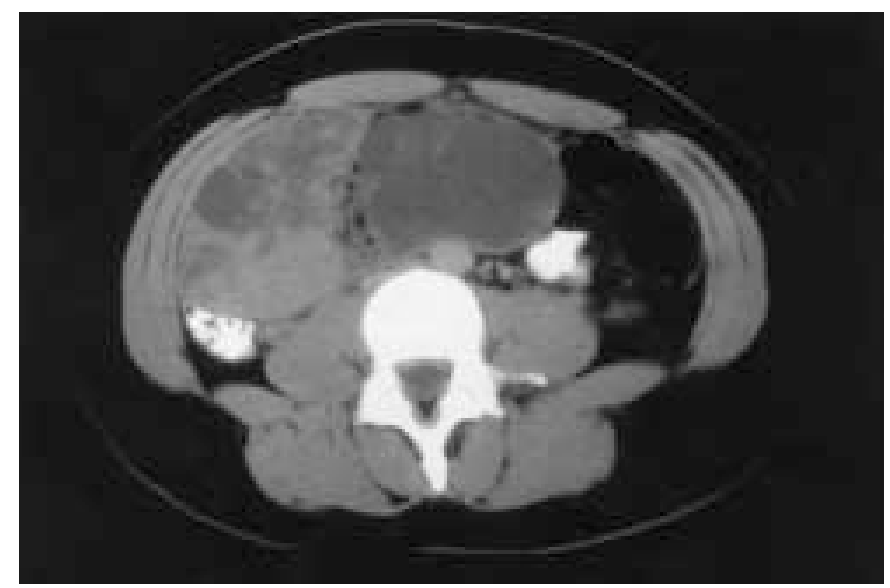

Fig. 1. Computerized tomography of a 16-year-old girl with an ovarian mixed malignant GCT with yolk sac tumor and immature teratoma components (with kind permission of the Institute for Diagnostic Radiology, Heinrich-Heine University, Düsseldorf).

\section{Introduction}

The past two decades have been characterized by a dramatic improvement of the prognosis of malignant germ cell tumors (GCT) both in the adult and in the pediatric population. This can mainly be attributed to national and international cooperative therapeutic protocols that utilized cisplatinum-based combination chemotherapy integrated into a multimodal therapeutic approach. Although the first pediatric trials have been designed in the light of the previous experience in malignant testicular GCT in adults, these studies have soon revealed the particular clinical and biological features of childhood GCT. Moreover, the early observations have allowed tailoring therapy more specifically to the pediatric setting and introducing stratification of chemotherapy according to distinct risk groups.

This review summarizes the rapid development during recent years, and describes what should be considered up-to-date therapy of pediatric GCT. Lastly, this article outlines possible future perspectives for treatment stratification that aim for lower short- and long-term toxicity but maintain high overall cure rates.

\section{Epidemiology}

In the pediatric age group, malignant GCT contribute $2.9 \%$ to the central Tumor Registry of the German Society for Pediatric Oncology and Hematology [1]. In Germany the incidence of malignant GCT is $0.6 / 100,000$ children up to 15 years old. Since teratomas contribute additional $50 \%$, the overall incidence of GCT can be estimated as 0.9/100,000. The distribution of GCT with regard to tumor site and histology varies significantly with age. In neonates mature and immature teratomas predominate. In the first years of life the overall inci-

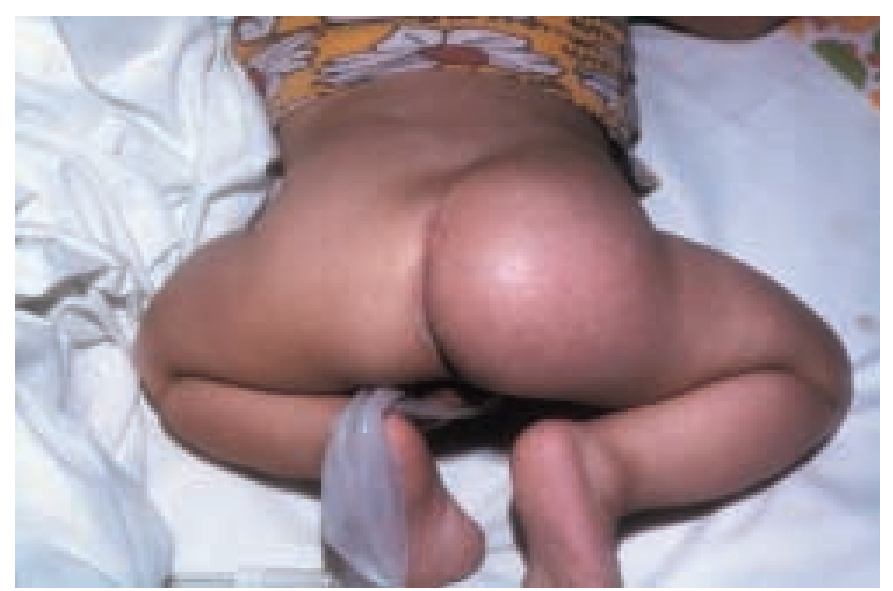

Fig. 2. Local recurrence of a sacrococcygeal yolk sac tumor with pronounced gluteal swelling.

dence of GCT decreases, but among toddlers the relative proportion of malignant tumors such as yolk sac tumors (YST) increases. The incidence of gonadal tumors, mainly seminomas and dysgerminomas, increases with the onset of puberty. In young men GCT represent the most common malignant tumor at all. Figures 1-5 show typical examples of gonadal and nongonadal GCT.

\section{Histologic Classification of Germ Cell Tumors}

GCT are characterized by a profound heterogeneity of their histologic differentiation. They are classified according to the WHO classifications of testicular, ovarian or intracranial tumors [2-4]. In our experience, these classifications constitute a more precise morphologic description than the British classification as they allow outlining all histologic components of mixed malignant GCT. As intratumor heterogeneity may be subtle, the initial diagnostic work-up should include the evaluation by an experienced pediatric pathologist. According to the guidelines of the German GCT protocols, a central histologic evaluation is mandatory in order to achieve a standardized and reliable histopathologic diagnosis and grading.

According to the holistic concept of Teilum [5, 6], GCT arise from totipotent primordial germ cells which are capable of embryonic and extraembryonic differentiation. YST and choriocarcinoma (CHC) follow an extraembryonic differentiation pattern and are characterized by significant secretion of alpha1-fetoprotein (AFP) and human choriogonadotropin (HCG or $\beta$-HCG), respectively (table 1) [7]. Embryonal carcinoma (EC) represent tumors of immature totipotent cells. Teratomas may mimic organ structures of all germ layers. The histologic grade of immaturity of teratoma is defined by the extent of immature (predominantly neuroepithelial) elements [8]. Finally, germinomatous tumors (synonyms: seminoma 


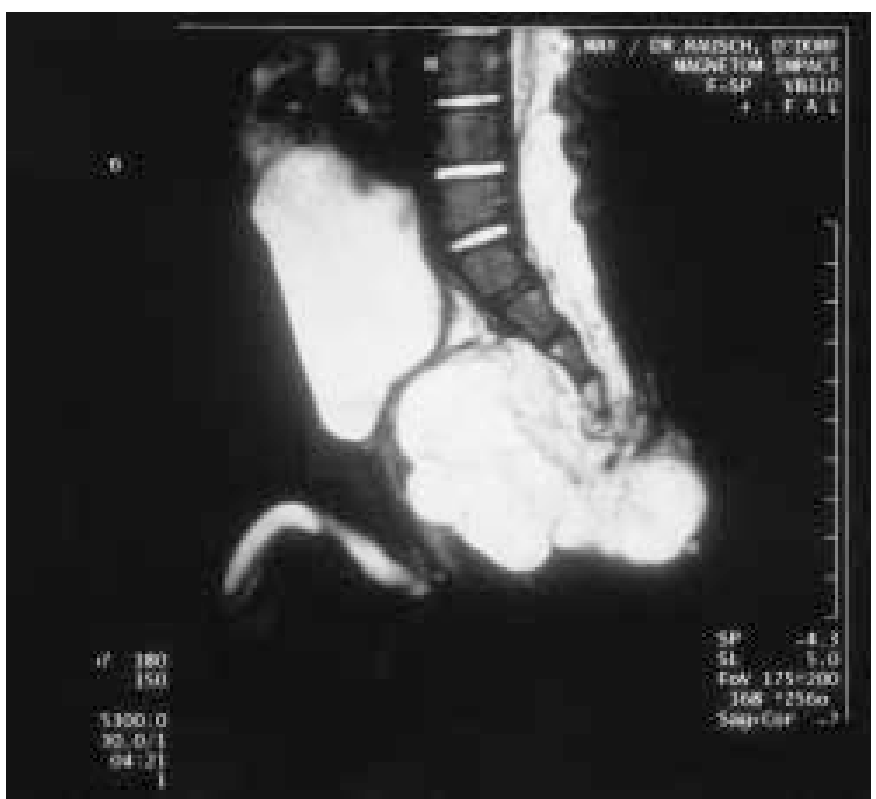

Fig. 3. Sagittal magnetic nuclear resonance tomography of an 18 -monthold-boy with a sacrococcygeal yolk sac tumor showing small extrapelvine and large intrapelvine tumor components and pronounced tumor extension into the spinal canal (with kind permission of Dr. May, Dr. Rausch, Diagnostic Radiologists, Düsseldorf)

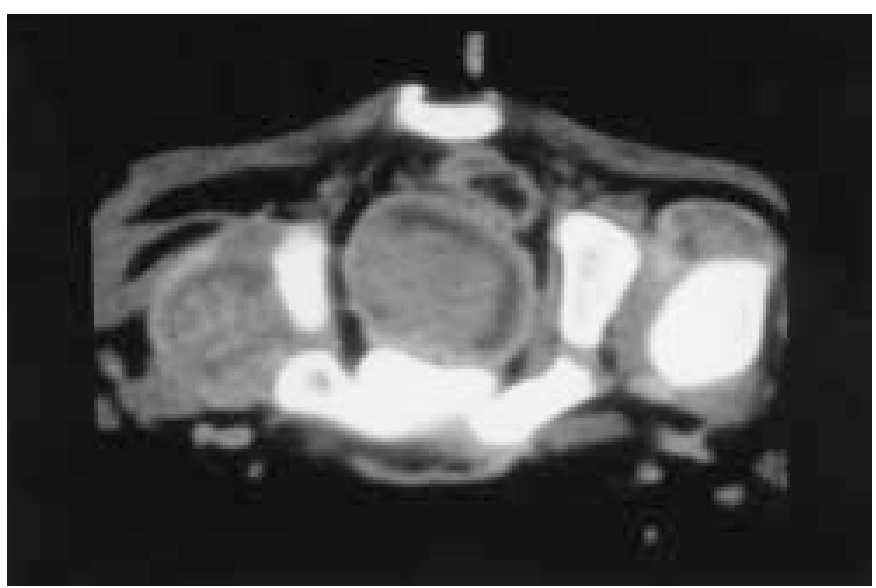

Fig. 4. Computerized tomography of a 4-month-old girl with a vaginal yolk sac tumor (with kind permission of the Institute for Diagnostic Radiology, Heinrich-Heine University, Düsseldorf).

(testis), dysgerminoma (ovary), germinoma (brain)) display morphological features of undifferentiated germ epithelium. In contrast to testicular GCT of adult patients, pediatric GCT do not develop from carcinoma in situ [9].

In most patients, the response to the different therapeutic modalities can be predicted from the histologic appearance and the tumor marker profile (table 1 ). About $25 \%$ of all pediatric GCT present as tumors with more than one histologic type. In this situation therapy and prognosis depend on the component with the highest malignancy.

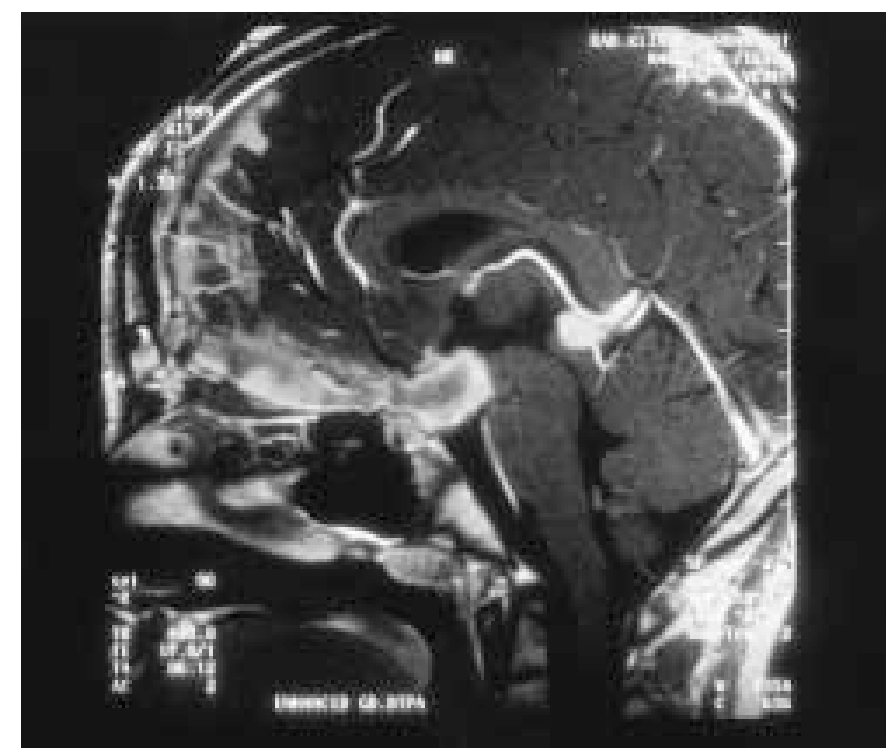

Fig. 5. Sagittal magnetic nuclear resonance tomography of an 12-yearold girl with an intracranial germinoma showing two tumor foci at the pineal and suprasellar region (with kind permission of the Institute for Diagnostic Radiology, Inner City Medical Center, Ludwig-Maximilians University, Munich).

\section{Tumor Markers}

The tumor markers AFP and/or $\beta$-HCG are helpful for clinical diagnosis in tumors that present at a typical localization (table 1) [7]. However, it has to be considered that serum AFP may be excessively elevated in neonates and infants [10]. Therefore, in the first 2 years of life only AFP levels significantly above the age-related normal value can be regarded as diagnostic for a secreting GCT. In general, the tumor marker profile is highly specific for the histologic differentiation of the tumors (table 1). However, there may be a secretion of $\beta$ chains of HCG in seminoma/germinoma $(<50 \mathrm{IU} / 1)$ related to syncytiotrophoblast-like giant cells. Some patients with immature teratoma may show a moderate elevation of the AFP level $(<100 \mu \mathrm{g} / \mathrm{l})$, sometimes associated with histologically detectable small foci of YST within the teratoma [11].

\section{Biology}

Molecular studies of the imprinting status of GCT revealed that gonadal and nongonadal GCT share a common cellular origin, the primordial germ cell although at different stages of their development [12-14]. These data substantiate the hypothesis that nongonadal GCT develop from germ cells that have mislocated during their embryonic development.

Pediatric GCT show a pattern of cytogenetic aberrations different from their adult counterparts. More than $80 \%$ of adult malignant GCT display a distinct and specific chromosomal aberration, the isochromosome $12 p$ [15]. The remaining 
Table 1. Biological characteristics of the histologic germ cell tumor subentities

\begin{tabular}{|c|c|c|c|c|c|}
\hline & \multirow[t]{2}{*}{ Histological grading } & \multicolumn{2}{|c|}{ Tumor markers } & \multicolumn{2}{|l|}{ Sensitivity to } \\
\hline & & AFP & B-HCG & chemotherapy & radiotherapy \\
\hline Seminoma/germinoma & malignant & - & $(+)$ & +++ & $\geq 24$ Gy \\
\hline EC & malignant & - & - & +++ & $\geq 45 \mathrm{~Gy}$ \\
\hline YST & malignant & +++ & - & +++ & $\geq 45 \mathrm{~Gy}$ \\
\hline $\mathrm{CHC}$ & malignant & - & +++ & +++ & $\geq 45 \mathrm{~Gy}$ \\
\hline Teratoma, mature/immature & benign/potentially malignant & $-/(+)$ & - & $?$ & $?$ \\
\hline
\end{tabular}

isochromosome $12 \mathrm{p}$-negative tumors frequently show amplification of $12 p$ (homogeneously staining regions or tandem repeats). These aberrations have been observed in both testicular and ovarian tumors and in mediastinal GCT.

In children younger than 10 years an isochromosome $12 \mathrm{p}$ has been found only in a small minority of malignant GCT [16, 17]. On the other hand, aberrations at both the short and the long arm of chromosome 1, at the long arm of chromosome 6 and of the sex chromosomes have been found frequently [16]. Lastly, virtually all prepubertal teratomas are normal on conventional cytogenetic analysis or on comparative genomic hybridization [17-19].

\section{Therapy}

\section{The Pre-Platinum Era}

Until 1980, the prognosis of children with malignant GCT was poor, and outcome was determined by the parameters age, site, histology and stage. Only low-stage testicular YST in children younger than 2 years and ovarian dysgerminoma had a more favorable prognosis after radical resection [20-23].

The introduction of adjuvant chemotherapy with vincristin, actinomycin D, and cyclophosphamide (VAC) in the 1960s constituted a first and important step towards cure as for the first time lasting complete remissions were achieved in a significant proportion of patients [24-26]. However, the cure rates in nonseminonatous GCT were still unsatisfactory as a result of relapses during the first 2 years of follow-up.

\section{Cisplatinum Chemotherapy}

The modern era of GCT chemotherapy began in the mid 1970s with the identification of the efficacy of cisplatinum in testicular GCT. In 1977, Einhorn and Donohue [27] reported a complete response rate of $85 \%$ in patients with metastatic testicular GCT with a combination of cisplatinum, vinblastin, and bleomycin (PVB) after tumor resection. Most importantly, the overall good response was also translated into durable remissions. Nevertheless, relapses or refractory cancers - although rare - established the need for second-line therapies, and etoposide soon emerged as an active drug with a singleagent efficacy superior to vinblastin [28]. In addition, the efficacy of ifosfamide in cisplatinum-refractory GCT has been documented. The combination of cisplatinum with etoposide and ifosfamide for recurrent testicular GCT results in a $30 \%$ durable remission rate and can now be considered standard relapse treatment [29].

In relapsing and refractory GCT, the therapeutic value of high-dose chemotherapy with autologous stem cell transplantation has been investigated. These analyses have shown only limited efficacy in prognostically unfavorable tumors such as cisplatinum-resistant, mediastinal GCT with high $\beta$-HCG or multiple relapses [30]. Nevertheless, in some patients introduction of high-dose chemotherapy into first-line treatment of high-risk tumors may be beneficial [31]. Lastly, 'modern' drugs such as paclitaxel and gemcitabine are currently under investigation.

\section{Development of Cooperative Protocols for Pediatric GCT}

Encouraged by the data discussed above, prospective pediatric protocols for gonadal and nongonadal GCT were initiated. The first published trial was conducted by the US Children's Cancer Group (CCG) and included 54 children with malignant nonseminomatous GCT. Patients underwent initial resection followed by VAC + PVB chemotherapy over a 2year period [32]. 15 of 20 evaluable patients with ovarian nonseminonatous GCT achieved complete remission. The prognosis of children with nongonadal GCT was worse (complete remission in $10 / 18$ patients) but still encouraging compared to all other previous studies.

The consecutive CCG protocol included 93 children and confirmed the previous observation that gonadal GCT were more favorable than nongondadal GCT (4-year event-free survival (EFS) rates $63 \%$ vs. $42 \%$ ) [33]. This difference was mainly attributed to a higher rate of complete resections in gonadal tumors. 
In the consecutive US Intergroup protocol, the therapeutic impact of cisplatinum dose intensification at $200 \mathrm{mg} / \mathrm{m}^{2} /$ cycle was evaluated. The interim analysis and the analysis of sacrococcygeal GCT reveal that cisplatinum escalation may increase the therapeutic efficacy, however at an apparently higher renal and auditory toxicity $[34,35]$.

The analysis of the UKCCSG (United Kingdom Children's Cancer Study Group) study on malignant germ cell tumors registered between 1979 and 1987 [36] included several chemotherapy regimens: Low-dose VAC treatment was seen to be ineffective (EFS rate $8 \%$ ). The PVB combination (days $2,9,16)$ caused unacceptable pulmonary toxicity due to bleomycin, whereas the combination of bleomycin (day 1 only), etoposide and cisplatinum (BEP) showed superior results with no proven pulmonary complication (EFS rate $84 \%$ ). Further analysis and comparison of different regimens of the UKCCG GC I and GC II protocols also demonstrated the high efficacy of platinum-based regimens such as BEP and JEB (carboplatinum ( $600 \mathrm{mg} / \mathrm{m}^{2} /$ cycle), etoposide, bleomycin) that resulted in a 5 -year EFS rate of $57 \%$ and $87 \%$ in nongonadal GCT, respectively [37]. The recent analysis of the UKCCG GC II study underscores the high efficacy of the JEB regimen that resulted in a 5-year EFS rate of $88 \%$ [38].

The French study group first reported 35 children with ovarian and nongonadal advanced-stage GCT treated with a VAC + $\mathrm{PB}$ regimen (2-year survival rate 63\%) [39]. In the consecutive TGM 90 protocol, cisplatinum was replaced by carboplatinum (400 mg/m²/cycle) [40, 41]. This regimen produced less favorable results than the British JEB regimen that used higher single and cumulative doses of carboplatinum. In the current French protocol, alternating combinations of cisplatinum with etoposide or ifosfamide are administered, resulting in superior response compared to the previous carboplatinum-based strategy.

In both the French TGM 90 and the British GC II studies, the analysis of prognostic factors revealed the impact of high AFP serum levels at diagnosis, a finding that could not be confirmed by other studies that used a cisplatinum-based regimen $[42,43]$ as well as the ongoing French protocol.

From 1982 on, the German protocols for testicular (MAHO) and nontesticular (MAKEI) GCT included cisplatinum- and etoposide-based regimens integrated into a multimodal approach that included delayed resection after preoperative or neoadjuvant chemotherapy for advanced tumors [42-47]. As a consequence of the excellent EFS rates above $80 \%$ achieved with the first protocols, cumulative chemotherapy was stepwise reduced from 8 cycles to 6 and currently to 4-5 cycles. This reduction of cumulative chemotherapy did not affect outcome $[42,43]$.

In summary, the regimens PEI (cisplatinum, etoposide and ifosfamide), BEP, CarboPEI (carboplatinum, etoposide and ifosfamide), and JEB have a synergistic cytotoxic activity and can be regarded as standard regimens with comparable efficacy that are applied in currently open pediatric GCT protocols.

\section{Side Effects of Chemotherapy}

Pulmonary toxicity of bleomycin appears to be particularly problematic in combination with impaired kidney function [48] or under anesthesia [49]. As a consequence, regimens such as PEI that excluded bleomycin were evaluated. The highly efficient combination PEI is associated with higher myelosuppression and bears the risk of tubular nephropathy [50]. In our experience with this regimen, we observed clinically apparent hearing impairment in approximately $20 \%$ of patients. Although auditory and renal toxicity of the carboplatinum regimen are smaller, carboplatinum at effective doses $\left(600 \mathrm{mg} / \mathrm{m}^{2} /\right.$ cycle) bears a substantial myelotoxicity [38]. The risk of therapy-related secondary leukemia is dependent on the applied therapeutic modalities with an estimated cumulative risk of $1.0 \%$ (3/442 patients, Kaplan-Meier method at 10-year follow-up) for children treated with surgery and chemotherapy only and 4.2\% (3/174 patients) for children treated with combined radio- and chemotherapy [51]. Nevertheless, the risk-benefit analysis still favors the use of etoposide in first-line treatment because of its excellent cytostatic effect in childhood GCT.

\section{Therapeutic Strategies of the International SIOP CNS GCT 96 Protocol and the Currently Open German Protocols for Extracranial Germ Cell Tumors}

The general therapeutic strategy may vary between different protocols. Some protocols stratify the cumulative chemotherapy according to the response to treatment (e.g. one standard chemotherapy regimen to a total of 2 cycles after complete remission $[37,38])$. In other protocols, therapy is stratified according to initial diagnostic parameters. In the following sections, the SIOP CNS GCT 96 protocol and the German protocols for extracranial GCT and their risk-adapted therapeutic strategies are summarized.

\section{SIOP CNS GCT 96 Protocol on Malignant Intracranial GCT}

Therapy for malignant intracranial GCT is stratified according to the histologic differentiation (i.e. germinoma vs. malignant nongerminomatous GCT) and stage. The ongoing SIOP CNS GCT protocol evaluates two therapeutic options in intracranial germinoma with regard to both their therapeutic impact and their specific acute and long-term toxicity. For malignant nongerminomatous intracranial tumors, the effect of combined treatment with PEI and risk-adapted radiotherapy is examined.

In germinoma (fig. 5), which account for $50 \%$ of all intracranial GCT and do not secret significant amounts of $\beta-\mathrm{HCG}$, histologic sampling is mandatory. According to the current SIOP CNS GCT 96 protocol, patients can be treated either 
with craniospinal irradiation with $24 \mathrm{~Gy}$ and tumor boost of 16 Gy or with a multimodal treatment including two cycles of chemotherapy (CarboPEI) followed by focal irradiation (40 Gy). With radiotherapy only, a 5-year EFS rate of 91\% and 5year overall survival rate of $94 \%$ can be achieved [52]. With the combined chemo- and radiotherapy approach, a 3-year relapse-free survival rate of $96 \%$ and an overall 3-year survival rate of $98 \%$ have been reported. However, it should be considered that in this study 2 of the 4 observed events occurred after the evaluated 3-year observation period [53]. Lastly, strategies that excluded radiotherapy have not resulted in sufficient tumor control [54].

Malignant nongerminomatous intracranial GCT (YST, CHC, EC) have an inferior prognosis compared to germinoma. In these patients 4 cycles of PEI are applied, followed by delayed resection and radiotherapy. Radiotherapy is stratified according to initial staging. Nonmetastatic tumors receive focal irradiation (54 Gy), whereas patients with intracranial or spinal metastases or tumor cells in the cerebrospinal fluid receive craniospinal irradiation ( $30 \mathrm{~Gy}$ plus $24 \mathrm{~Gy}$ tumor boost). The meta-analysis of several cooperative protocols suggests that a long-term remission can be obtained in about two thirds of patients [55]. Again, strategies that exclude radiotherapy yield inferior results [54].

\section{MAHO and MAKEI Protocols on Extracranial Malignant GCT}

\section{Surgical Treatment}

Both gonadal and extragonadal GCT are treated according to a similar therapeutic concept: Only in small tumors with no evidence of invasive growth beyond the organ of origin or of metastases, primary resection is recommended. In patients with bulky, invasive or metastatic tumors, a preoperative chemotherapy followed by delayed resection is preferred to avoid incomplete resection. The decline of the tumor markers according to their serum half-lifes indicates for a favorable response to chemotherapy $[7,10,56]$.

Resection is considered complete if performed as en-bloc resection of the tumor including the adjacent organ of origin. The resection margins must be histologically free of tumor cells. In testicular tumors, a high inguinal orchidectomy is mandatory, and tumor biopsy is obsolete. Ovarian tumors (fig. 1) must be resected including ovary and Fallopian tube. In coccygeal tumors (fig. 2,3) the complete en toto resection including the whole coccyx is essential $[42,57]$. Additional attention should be paid to potential extension of the tumor into the spinal canal, which can be recognized on nuclear magnetic resonance tomography (fig. 3). In this situation, preoperative chemotherapy is advisable. A recently published review summarizes the standard surgical procedures in gonadal and extragonadal GCT in detail [58]. The rare vaginal YST of infancy (fig. 4) constitute the only exception as these very chemosensitive tumors may also be cured without - according to oncologic standards - radical resection [59].

In patients with residues after initial tumor resection, secondlook surgery is essential. Second-look surgery may at least partly overcome the otherwise unfavorable prognostic impact of incomplete resection [42, 43]. In general, there is no role for debulking surgery in pediatric GCT. Usually, surgery of metastases is not indicated unless they show insufficient response to chemotherapy [42, 46, 60].

\section{Adjuvant Treatment}

According to the MAHO 98 protocol for testicular GCT, patients with stage IA mature teratoma or YST are treated expectantly. All other patients receive $2-3$ cycles PVB $(\leq$ stage IIB) or the more intensive BEP (stages IIC-IV). PEI is reserved to salvage therapy in patients with relapsing or poorly responding tumors.

In the current MAKEI 96 protocol, patients with completely resected stage T1 tumors are treated according to a watchand-wait strategy which includes frequent (weekly) controls of the relevant tumor markers. Completely resected stage T2 tumors receive 2-3 cycles of a two-agent regimen (PE). A three-agent combination is applied after incomplete resection (PEI) [61]. Ovarian dysgerminoma are treated according to the same strategy. Irradiation is omitted to preserve fertility.

\section{Teratoma}

Teratomas represent a distinct histologic entity that shows a significant diversity of the clinical course in dependence of the histologic grade of immaturity [8, 57]. Mature teratomas are considered benign tumors, whereas immature teratomas may show clinical features of malignancy. Surgical treatment should follow the same principles as outlined above for malignant GCT.

The risk of recurrence can be estimated from the following parameters: primary site of the tumor, histologic grade of immaturity, and completeness of the tumor resection [57].

The role of adjuvant chemotherapy has not yet been established. However, recent reports have shown that chemotherapy may not be indicated after complete resection, even in the presence of small foci of YST [57, 62]. Incompletely resected tumors have a $10 \%$ risk of relapse in mature and a $20 \%$ risk in immature teratomas [57]. Half of the recurrent tumors may display YST or EC histology. Adjuvant chemotherapy did not reduce the risk of recurrence. However, no malignant relapses have been seen after previous chemotherapy.

\section{Follow-Up}

Complete clinical remission is defined as normalization of tumor markers within the age-related normal range and the absence of suspicious residual structures. If any of these criteria are not fulfilled, a diagnostic re-evaluation and - if neces- 
sary - change or intensification of treatment is urgently indicated. Most relapses occur within the first 2 years after diagnosis. However, in some patients late recurrences 5 years or later after diagnosis have been observed. Initial follow-up examinations after completion of chemotherapy must be performed in short intervals, including frequent (i.e. weekly) controls of the tumor markers AFP and $\beta$-HCG early during follow-up. In watch-and-wait patients, the decline of the AFP values must be evaluated with regard to its serum half-life of approximately 6-7 days. Especially in infants younger than 2 years, the interpretation of AFP may be difficult due to the physiologically elevated serum levels. In this context, it has been proven helpful to compare the AFP decline to the agerelated reference values in neonates and infants [10]. A retarded decline or a secondary rise of the AFP levels strongly indicates for incomplete tumor resection or a recurrence of YST [7].

In addition, follow-up must include repeated imaging of the primary site of tumor. In case of residual structures after chemotherapy of extracranial GCT, resection is indicated since mature teratoma may have remained and bear the risk of tumor progression [63]. In our experience, positron emission tomography examinations have not been proven useful in this situation as these cannot distinguish between mature teratoma and residual necrosis or scars [64].

In intracranial tumors, repeated endocrinologic examinations at diagnosis and during follow-up are mandatory since especially tumors of the suprasellar region can be associated with diabetes insipidus or panhypopituiarism. In children treated with cisplatinum and/or ifosfamide, the renal function has to be monitored carefully for tubular nephropathy. In children, a prolonged phosphaturia may lead to renal rickets with consecutive growth retardation while adolescents are at risk of renal osteomalacia [50]. These long-term sequelae can be avoided by supplementation of phosphate. Further attention should be drawn to the risk of therapy-related secondary leukemia that depends on treatment intensity and modality.

\section{Relapse Treatment}

In patients with recurrent or refractory tumors who had previously been treated with a non-platinum or carboplatinum therapy, cisplatinum-based regimens (preferably PEI) have been applied successfully [40,61]. Therefore, we prefer cisplatinum-containing regimens in patients with relapsed tumors if the organ toxicity related to the previous treatment allows further cisplatinum therapy. On the other hand, patients with severe cisplatinum-related toxicity may be treated with a combination of carboplatinum and high-dose etoposide (at $400-600 \mathrm{mg} / \mathrm{m}^{2}$ on 3 days). In our experience, high-dose chemotherapy with stem cell support, as it has been applied in adult patients [61], resulted in long-term remissions only in those patients in whom a clinical complete remission could be achieved prior to high-dose chemotherapy [60]. Therefore, we would tend to reserve high-dose chemotherapy to consolidation treatment.

In our experience, more than $90 \%$ of relapses occur at the primary site of the tumor. For example, in our series of 104 sacrococcygeal YST only 2 patients had distant recurrences, whereas 17 patients had local and 3 patients combined local and distant relapses [60]. Therefore, relapse chemotherapy must be accompanied by an intensive local therapy, preferably complete resection of the recurrent tumor after tumor reduction by preoperative chemotherapy. We could demonstrate that patients with local recurrences and poor response to conventional chemotherapy may benefit from locoregional hyperthermia combined with platinum-based chemotherapy. This approach significantly enhanced local tumor control [60, 65, 66]. However, the analysis of recurrent sacrococcygeal GCT underscored the need to implement hyperthermia early as in late relapse situations hyperthermia showed no beneficial effect, probably as a result of cisplatinum resistance or delayed chemotherapy due to myelotoxicity of the previous treatment [60]. Lastly, high-dose local irradiation at doses above 45 Gy has shown some beneficial effects after incomplete resection of the tumor recurrence, whereas irradiation at lower doses was ineffective [60].

As insufficient local tumor control at the primary site of tumor represents the main problem in most patients, further significant advances in relapsing GCT may probably be based on further improvement of local therapy.

\section{Future Perspectives}

A multimodal approach that utilizes cisplatinum/etoposide chemotherapy as well as tumor resection is highly effective for the treatment of pediatric GCT. In the light of the high cure rates achieved by current protocols, research must now focus on new aims. First, treatment must be further intensified in those patients with cisplatinum-refractory or poorly responding tumors. The US study group evaluates a further dose escalation of cisplatinum under protection with amifostine as a 200 $\mathrm{mg} / \mathrm{m}^{2} /$ cycle cisplatinum dose yielded a small but significant survival advantage compared to a $100 \mathrm{mg} / \mathrm{m}^{2} /$ cycle dose. However, results regarding toxicity are still pending. Furthermore, results of alternative high-dose chemotherapy studies in recurrent GCT have to be awaited. Locoregional hyperthermia constitutes an attractive alternative as cisplatinum represents a very good thermosensitizer and hyperthermia may therefore overcome cisplatinum resistance $[60,65,66]$. In addition, locoregional hyperthermia should hopefully result in less systemic side effects than cisplatinum dose escalation.

On the other hand, patients should be identified that are only at a low risk of relapse and in whom adjuvant chemotherapy can either be withheld or significantly reduced, thus allowing 
to minimize the impact on short- and long-term quality of life and treatment toxicity.

In this context, molecular genetic studies may also reveal some important information that may be utilized for risk stratification. For example, in mediastinal GCT, genetic analysis distinguishes two distinct genetic profiles by age that may correlate with a poor (adults) or favorable (infants) prognosis [19].

In conclusion, in the future clinical and molecular biologic information may allow distinguishing low-risk from high-risk patients accurately and thereby allow designing a multimodal approach to the individual patient.

\section{Acknowledgement}

The authors thank the Deutsche Krebshilfe e.V., Bonn and the German Federal Ministry for Science and Technology (BMFT Nr.01 ZP 850 12) for the support of the German Germ Cell Tumor program. The authors gratefully acknowledge Susanne Koch and Carmen Teske for expert data management and Carmen Grüttner for secreterial work. The authors thank all 229 medical centers that contributed their patients to the MAHO, MAKEI and SIOP CNS GCT studies. The validity of the clinical data is based on this long-standing support over the last 20 years.

\section{References}

1 Kaatsch P, Kaletsch U, Michaelis J: Annual Report 1997; German Childhood Cancer Registry. Mainz, Deutsches Kinderkrebsregister, 1998.

2 Serov SF, Scully RE: Histological Typing of Ovarian Tumors. Geneva, World Health Organization, 1973.

3 Mostofi FK, Sobin LH: Histopathological Typing of Testis Tumors. Geneva, World Health Organization, 1993.

4 Kleihues P, Burger PC, Scheithauer BW: The new WHO classification of brain tumours. Brain Pathol 1993:3:255-268.

5 Teilum G: Classification of endodermal sinus tumour (mesoblastoma vitellinum) and so-called 'embryonal carcinoma' of the ovary. Acta Pathol Microbiol Scand 1965;64:407-429.

6 Gonzalez-Crussi F: Extragonadal Teratomas. Atlas of Tumor Pathology, Second Series, Fascicle 18. Washington, D.C., AFIP, 1970.

7 Schneider DT, Calaminus G, Göbel U: Diagnostic value of alpha 1 -fetoprotein and human chorionic gonadotropic hormone in infancy and childhood. Pediatr Hematol Oncol 2001;18:11-26.

8 Gonzalez-Crussi F, Winkler RF, Mirkin DL: Sacrococcygeal teratomas in infants and children: Relationship of histology and prognosis in 40 cases. Arch Pathol Lab Med 1978;102:420-425.

9 Hawkins E, Heifetz SA, Giller R, Cushing B: The prepubertal testis (prenatal and postnatal): Its relationship to intratubular germ cell neoplasia: A combined Pediatric Oncology Group and Children's Cancer Study Group. Hum Pathol 1997;28: 404-410.

10 Blohm ME, Vesterling-Hörner D, Calaminus G, Göbel U: Alpha 1-fetoprotein (AFP) reference values in infants up to 2 years of age. Pediatr Hematol Oncol 1998;15:135-142.

11 Heifetz SA, Cushing B, Giller R, Shuster JJ, Stolar CJ, Vinocur CD, Hawkins EP: Immature teratomas in children: Pathologic considerations: A report from the combined Pediatric Oncology Group/ Children's Cancer Group. Am J Surg Pathol 1998; 22:1115-1124.

12 Schneider DT, Schuster AE, Fritsch MK Hu J, Olson T, Lauer S, Gobel U, Perlman EJ: Multipoint imprinting analysis indicates a common precursor cell for gonadal and nongonadal pediatric germ cell tumors. Cancer Res 2001,61:7268-7276.

13 van Gurp RJ, Oosterhuis JW, Kalscheuer V, Mariman EC, Looijenga LH: Biallelic expression of the $H 19$ and $I G F 2$ genes in human testicular germ cell tumors. J Natl Cancer Inst 1994;86:1070-1075.
14 Miura K, Obama M, Yun K, Masuzaki H, Ikeda Y, Yoshimura S, Akashi T, Niikawa N, Ishimaru T, Jinno Y: Methylation imprinting of H19 and $S N R P N$ genes in human benign ovarian teratomas. Am J Hum Genet 1999;65:1359-1367.

15 Chaganti RS, Houldsworth J: Genetics and biology of adult human male germ cell tumors. Cancer Res 2000;60:1475-1482.

16 Perlman EJ, Hu J, Ho D, Cushing B, Lauer S, Castleberry RP: Genetic analysis of childhood endodermal sinus tumors by comparative genomic hybridization. J Pediatr Hematol Oncol 2000;22: 100-105.

17 Bussey KJ, Lawce HJ, Olson SB, Arthur DC, Kalousek DK, Krailo M, Giller R, Heifetz S, Womer R, Magenis RE: Chromosome abnormalities of eighty-one pediatric germ cell tumors: sexage-, site-, and histopathology-related differences a Children's Cancer Group study. Genes Chromosomes Cancer 1999;25:134-146.

18 Schneider DT, Schuster AE, Fritsch MK, Calaminus G, Harms D, Gobel U, Perlman EJ: Genetic analysis of childhood germ cell tumors with comparative genomic hybridization. Klin Pädiatr 2001; 213:204-211.

19 Schneider DT, Schuster AE, Fritsch MK, Calaminus G, Göbel U, Harms D, Lauer S, Olson T, Perlman EJ: Genetic analysis of mediastinal nonseminomatous germ cell tumors in children and adolescents. Genes Chromosomes Cancer 2002:(in press).

20 Asadourian LA, Taylor HB: Dysgerminoma. An analysis of 105 cases. Obstet Gynecol 1969;33: 370-379.

21 Bamberg M, Schultz U, Scherer E: Clinical manifestations and therapy of dysgerminomas. Strahlentherapie 1981;157:290-296.

22 Caldwell WL, Kademian MT, Frias Z, Davis TE: The management of testicular seminomas, 1979. Cancer 1980;45:1768-1774.

23 Brodeur GM, Howarth CB, Pratt CB, Caces J, Hustu HO: Malignant germ cell tumors in 57 children and adolescents. Cancer 1981;48:1890-1898.

24 Wollner N, Exelby PR, Woodruff JM, Cham WC, Murphy ML, Lewis JL Jr: Malignant ovarian tumors in childhood: Prognosis in relation to initial therapy. Cancer 1976;37:1953-1964.

25 Li MC, Whitmore R, Golbey R, Grabstald H: Effects of combined drug therapy on metastatic cancer of the testis. JAMA 1960;174:1291.

26 Smith JP, Rutledge F: Chemotherapy in the treatment of cancer of the ovary. Am J Obstet Gynecol 1970;107:691-703.
27 Einhorn LH, Donohue JP: Chemotherapy for disseminated testicular cancer. Urol Clin North Am 1977;4:407-426.

28 Williams SD, Einhorn LH, Greco FA, Oldham R, Fletcher R: VP-16 salvage therapy for refractory germinal neoplasms. Cancer 1980;46:2154-2158.

29 Nichols CR: Treatment of recurrent germ cell tumors. Semin Surg Oncol 1999;17:268-274.

30 Beyer J, Kramar A, Mandanas R, Linkesch W, Greinix A, Droz JP, Pico JL, Diehl A, Bokemeyer C, Schmoll HJ, Nichols CR, Einhorn LH, Siegert W: High-dose chemotherapy as salvage treatment in germ cell tumors: A multivariate analysis of prognostic variables. J Clin Oncol 1996;14:26382645.

31 Bokemeyer C, Kollmannsberger C, Meisner C, Harstrick A, Beyer J, Metzner B, Hartmann JT, Schmoll HJ, Einhorn L, Kanz L, Nichols C: Firstline high-dose chemotherapy compared with standard-dose PEB/VIP chemotherapy in patients with advanced germ cell tumors: A multivariate and matched-pair analysis. J Clin Oncol 1999;17:34503456.

32 Ablin AR: Malignant germ cell tumors in children. Front Radiat Ther Oncol 1981;16:141-149.

33 Ablin AR, Krailo MD, Ramsay NK, Malogolowkin MH, Isaacs H, Raney RB, Adkins J, Hays DM, Benjamin DR, Grosfeld JL: Results of treatment of malignant germ cell tumors in 93 children: A report from the Children's Cancer Study Group. J Clin Oncol 1991;9:1782-1792.

34 Rescorla F, Billmire D, Stolar C, Vinocur C, Colombani P, Cullen J, Giller R, Cushing B, Lauer S, Davis M, Hawkins E, Shuster J, Krailo M: The effect of cisplatin dose and surgical resection in children with malignant germ cell tumors at the sacrococcygeal region: A pediatric intergroup trial (POG 9049/CCG 8882). J Pediatr Surg 2001;36:1217.

35 Giller R, Cushing B, Lauer S, Marina N, Cohen L, Ablin A, Cullen J, Rogers P, Weetman R, Colombani P, Rescorla F, Hawkins E, Heifetz S, Rao P, Krailo M, Castleberry R: Comparison of high-dose or standard cisplatin with etoposide and bleomycin (HDPEB vs. PEB) in children with stage III and IV malignant germ cell tumors (MGCT) at gonadal primary sites: A pediatric intergoup trial (POG 9049/CCG8882). Proc ASCO 1998;34:2016.

36 Mann JR, Pearson D, Barrett A, Raafat F, Barnes JM, Wallendszus KR: Results of the United Kingdom Children's Cancer Study Group's malignant germ cell tumor studies. Cancer 1989;63:1657-1667. 
37 Mann JR, Raafat F, Robinson K, Imeson J, Gornall P, Phillips M, Sokal M, Gray E, McKeever P, Oakhill A: UKCCSG's germ cell tumour (GCT) studies: Improving outcome for children with malignant extracranial non-gonadal tumours - carboplatin, etoposide, and bleomycin are effective and less toxic than previous regimens. United Kingdom Children's Cancer Study Group. Med Pediatr Oncol 1998;30:217-227.

38 Mann JR, Raafat F, Robinson K, Imeson J, Gornall P, Sokal M, Gray E, McKeever P, Hale Bailey S, Oakhill A: The United Kingdom Children's Cancer Study Group's second germ cell tumor study: Carboplatin, etoposide, and bleomycin are effective treatment for children with malignant extracranial germ cell tumors, with acceptable toxicity. J Clin Oncol 2000;18:3809-3818.

39 Flamant F, Schwartz L, Delons E, Caillaud JM, Hartmann O, Lemerle J: Nonseminomatous malignant germ cell tumors in children. Multidrug therapy in stages III and IV. Cancer 1984;54:1687-1691.

40 Baranzelli MC, Kramar A, Bouffet E, Quintana E, Rubie H, Edan C, Patte C: Prognostic factors in children with localized malignant nonseminomatous germ cell tumors. J Clin Oncol 1999;17:12121219.

41 Baranzelli MC, Bouffet E, Quintana E, Portas M, Thyss A, Patte C: Non-seminomatous ovarian germ cell tumours in children. Eur J Cancer 2000;36: 376-383.

42 Göbel U, Schneider DT, Calaminus G, Jürgens H, Spaar HJ, Sternschulte W, Waag K, Harms D: Multimodal treatment of malignant sacrococcygeal germ cell tumors: A prospective analysis of $66 \mathrm{pa}-$ tients of the German cooperative protocols MAKEI 83/86 and 89. J Clin Oncol 2001;19:19431950.

43 Schneider DT, Calaminus G, Reinhard H, Gutjahr P, Kremens B, Harms D, Göbel U: Primary mediastinal germ cell tumors in children and adolescents: Results of the German cooperative protocols MAKEI 83/86, 89, and 96. J Clin Oncol 2000;18: 832-839.

44 Haas RJ, Göbel U, Harms D, Schmidt P, Weissbach L: Ergebnisse der kooperativen Therapiestudie für maligne Keimzelltumoren MAHO 82 der Deutschen Gesellschaft für Pädiatrische Onkologie. Klin Pädiatr 1988;200: 230-235.

45 Göbel U, Gutjahr P, Jürgens H, Kabisch H, Lampert F, Spaar HJ, Sternschulte W, Harms D: Die kooperative Therapiestudie für nicht testikuläre Keimzelltumoren MAKEI 83 der Gesellschaft für Pädiatrische Onkologie: Analyse nach 3 Jahren. Klin Pädiatr 1986;198: 237-244.
46 Göbel U, Calaminus G, Teske C, Bamberg M, Bokkerink JP, Haas RJ, Holschneider AM, JankaSchaub G, Jürgens H, Mittler U: BEP/VIP bei Kindern und Jugendlichen mit malignen nicht testikulären Keimzelltumoren. Ein Vergleich der Behandlungsergebnisse der Therapiestudien MAKEI 83/86 und 89P/89. Klin Pädiatr 1993;205:231-240.

47 Haas RJ, Schmidt P, Göbel U, Harms D: Testikuläre Keimzelltumoren. Ergebnisse der GPO MAHO -82, -88, -92 Studien Klin Pädiatr 1995;207: 145- 150 .

48 Dalgleish AG, Woods RL, Levi JA: Bleomycin pulmonary toxicity: Its relationship to renal dysfunction. Med Pediatr Oncol 1984;12:313-317.

49 Goldiner PL, Schweizer O: The hazards of anesthe sia and surgery in bleomycin-treated patients. Semin Oncol 1979;6:121-124.

50 Pratt CB, Meyer WH, Jenkins JJ, Avery L, McKay CP, Wyatt RJ, Hancock ML: Ifosfamide, Fanconi's syndrome, and rickets. J Clin Oncol 1991;9:14951499.

51 Schneider DT, Hilgenfeld E, Schwabe D, et al Acute myelogenous leukemia after treatment for malignant germ cell tumors in children. J Clin Oncol. 1999;17:3226-3233.

52 Bamberg M, Kortmann RD, Calaminus G, Becker G, Meisner C, Harms D, Göbel U: Radiation therapy for intracranial germinoma: Results of the German cooperative prospective trials MAKEI 83/86 89. J Clin Oncol 1999;17:2585-2592.

53 Bouffet E, Baranzelli MC, Patte C, Portas M, Edan C, Chastagner P, Mechinaud-Lacroix F, Kalifa C: Combined treatment modality for intracranial germinomas: Results of a multicentre SFOP experience. Societe Francaise d'Oncologie Pediatrique. Br J Cancer 1999;79:1199-1204.

54 Balmaceda C, Heller G, Rosenblum M, Diez B, Villablanca JG, Kellie S, Maher P, Vlamis V, Walker RW, Leibel S, Finlay JL: Chemotherapy without irradiation - a novel approach for newly diagnosed CNS germ cell tumors: Results of an international cooperative trial. The First International Central Nervous System Germ Cell Tumor Study. J Clin Oncol 1996;14:2908-2915.

55 Calaminus G, Bamberg M, Baranzelli MC, Benoit Y, di Montezemolo LC, Fossati-Bellani Jürgens H, Kuhl HJ, Lenard HG, Curto ML: Intracranial germ cell tumors: A comprehensive update of the European data. Neuropediatrics 1994;25:26-32.

56 Calaminus G, Vesterling-Hörner D, Bökkerink JP Gadner H, Gunther G, Haas HJ, Jürgens H, Teske C, Göbel U: Die Bedeutung des Serum $\alpha$ Fetoproteins (AFP) bei Kindern und Jugendlichen mit malignen extrakranialen nicht testikulären Keimzelltumoren. Klin Pädiatr 1991;203:246-250.
57 Göbel U, Calaminus G, Engert J, Kaatsch P, Gadner H, Bokkerink JP, Hass RJ, Waag K, Blohm ME, Dippert S, Teske C, Harms D: Teratomas in infancy and childhood. Med Pediatr Oncol 1998;31: $8-15$.

58 Rescorla F: Pediatric germ cell tumors. Semin Surg Oncol 1999;16:144-158.

59 Mauz-Körholz C, Harms D, Calaminus G, Göbel U: Primary chemotherapy and conservative surgery for vaginal yolk-sac tumour. Maligne Keimzelltumoren Study Group. Lancet 2000;355:625.

60 Schneider DT, Wessalowski R, Calaminus G, Pape $\mathrm{H}$, Bamberg M, Engert J, Waag K, Gadner H, Göbel U: Treatment of recurrent malignant sacrococcygeal germ cell tumors: Analysis of 22 patients registered in the German protocols MAKEI 83/86, 89, and 96. J Clin Oncol 2001;19:1951-1960.

61 Bosl GJ: Germ cell tumor clinical trials in North America. Semin Surg Oncol. 1999;17:257-262.

62 Marina NM, Cushing B, Giller R, Cohen L, Lauer SJ, Ablin A, Weetman R, Cullen J, Rogers P, Vinocur C, Stolar C, Rescorla F, Hawkins E, Heifetz S, Rao PV, Krailo M, Castleberry RP: Complete surgical excision is effective treatment for children with immature teratomas with or without malignant elements: A Pediatric Oncology Group/Children's Cancer Group intergroup study. J Clin Oncol 1999;17:2137-2143.

63 Stenning SP, Parkinson MC, Fisher C, Mead GM, Cook PA, Fossa SD, Horwich A, Jones WG, Newlands ES, Oliver RT, Stenwig AE, Wilkinson PM: Postchemotherapy residual masses in germ cell tumor patients: Content, clinical features, and prognosis. Medical Research Council Testicular Tumour Working Party. Cancer 1998;83:1409-1419.

64 Stephens AW, Gonin R, Hutchins GD, Einhorn LH: Positron emission tomography evaluation of residual radiographic abnormalities in postchemotherapy germ cell tumor patients. J Clin Oncol 1996;14:1637-1641.

65 Wessalowski R, Kruck H, Pape H, Kahn T, Willers R, Göbel U: Hyperthermia for the treatment of patients with malignant germ cell tumors: a phase I/II study in ten children and adolescents with recurrent or refractory tumors. Cancer 1998;82:793-800.

66 Wessalowski R, Blohm M, Calaminus G, Engert J, Harms D, Krause I, Kruck H, Gruttner HP, Pape H, Göbel U: Treatment results in children and adolescents with loco-regional recurrences of abdominal germ cell tumors (GCTs): A pilot-study with PEI chemotherapy and regional deep hyperthermia (RHT) in comparison to a matched cohort. Klin Pädiatr 1997;209:250-256. 